\title{
SPATIAL VELOCITY ELECTROCARDIOGRAM \\ OF THE P WAVE IN ATRIAL OVERLOAD
}

\author{
Hideo YASUdA
}

\begin{abstract}
The SVECG was recorded in grand total of 119 cases with mitral stenosis in 35 cases, atrial septal defect in 51 cases, tetralogy of Fallot in 22 cases and pulmonary stenosis in 11 cases, and the correlation with hemodynamic data in 107 cases and operation findings in 78 cases was investigated.

The atrial SVECG in atrial overloadings is composed of 3 types as seen in normal subjects: two-peaked, three-peaked and four-peaked patterns.

In the atrial SVECG of left atrial overloading, the first peak was considered to reflect the activation of right atrium and did not increase significantly in amplitude compared with normal subjects. The spatial velocity and time interval of the third and/or fourth peaks, which were considered to reflect mainly the depolarization of the left atrium, increased significantly. The $\mathrm{P}_{3} / \mathrm{P}_{1}$ and $\mathrm{P}_{4} / \mathrm{P}_{1}$ ratios had positive correlates with the mitral valvular area ascertained at surgical operation.

The atrial SVECG represents the right atrial overloading as a two-peaked pattern. Its incidence was high as in A SD group (65\%) as in TF (73\%) and PS $(73 \%)$ groups in spite of significantly lower right ventricular systolic pressure in ASD group than in TF and PS groups $(\mathbf{P}<0.01$ and $\mathbf{P}<0.01$ respectively). In $\mathrm{TF}$ group the right ventricular systolic pressure was significantly higher in the two-peaked subgroup than in the three-peaked one $(\mathrm{P}<$ $0.05)$.
\end{abstract}

$\mathbf{T}$

HE SPATIAL velocity electrocardiogram (SVECG) introduced by Hellerstein and Ham$\operatorname{lin}^{1}(1960)$ can represent the velocity of inscription of vector loops more precisely in comparison with the vectorcardiogram (VCG). Sano et al. (1963) and Mori et al. ${ }^{3}$ (1966) attempted to analyze the SVECG of normal individuals and patients with cardiac disorders using apparatus manufactured by themselves.

The present paper is concerned with quantitative as well as qualitative analysis of the atrial wave of SVECG in patients with atrial overload-

\footnotetext{
Key Words:

Spatial Velocity Electrocardiogram

P Wave

A trial Overload

Vectorcardiogram in A trial Overload (Frank System)

Intraatrial Conduction Disturbance
}

ing. Particular reference is made to the atrial wave of the SVECG in relation to hemodynamic data and findings ascertained at surgical operation.

\section{Materials AND Methods}

\section{Materials}

Sixty-one normal men aged 18 to 49 with an average age of 25.5 years were used as control subjects. ${ }^{4}$ One hundred and nineteen cases with atrial overloading were studied (Table I). These consisted of: 35 cases of pure mitral stenosis (MS), 51 cases of atrial septal defect of secundum type (ASD), 22 cases of tetralogy of Fallot (TF), and 11 cases of pure pulmonary stenosis (PS). Diagnosis of these disorders was made by physical examination, $\mathrm{x}$-ray examination, phonocardiography was performed in 107 cases (Table II). In 99 cases the diagnosis was ascertained

(Received for publication, May 4, 1973)

First Department of Medicine, Faculty of Medicine, Kyushu University, Fukuoka

(Director: Prof. Toshiyuki Yanase) 




Fig.1. Diagrammatic representation of measurements for the $\mathbf{P}$ wave of spatial velocity electrocardiogram (SVECG).

$\mathrm{X}, \mathrm{Y}$ and $\mathrm{Z}: 3$ scalar ECG's of Frank system. SV-P: the $\mathrm{P}$ wave of SVECG. $\quad P_{1}, P_{2}, P_{3}, N d 1$ and $N d 2$ : the first, second and third peaks and the first and second nadirs of the $P$ wave of SVECG respectively. SV-Pd: the P wave duration of SVECG.

TABLE I AGE AND HEART RATE IN SUBGROUPS OF NORMAL SUBJECTS AND THE PATIENTS WITH ATRIAL OVERLOAD

\begin{tabular}{|c|c|c|c|c|c|}
\hline \multirow{2}{*}{ Subjects } & \multirow{2}{*}{$\begin{array}{l}\text { Subgroups } \\
\text { of the P wave } \\
\text { of SVECG }\end{array}$} & \multirow{2}{*}{$\begin{array}{l}\text { Age (yrs.) } \\
\text { Mean (Range) }\end{array}$} & \multirow{2}{*}{$\begin{array}{l}\text { Heart rate } \\
\text { (beats } / \text { min) } \\
\text { Mean } \pm S D\end{array}$} & \multicolumn{2}{|c|}{ Numbers of cases } \\
\hline & & & & Subtotal (\%) & Total \\
\hline \multirow{3}{*}{ Normal } & 4-Peaked P & $25.1(20-31)$ & $67.9 \pm 9.8$ & $20(32.8)$ & \multirow{3}{*}{61} \\
\hline & 3-peaked $P$ & $25.7(18-38)$ & $69.3 \pm 10.7$ & $35(57.4)$ & \\
\hline & 2-peaked $P$ & $25.7(18-49)$ & $66.0 \pm 14.8$ & $6(9.8)$ & \\
\hline \multirow{2}{*}{$\begin{array}{l}\text { Mitral } \\
\text { Stenosis }\end{array}$} & 4-peaked $P$ & $34.1(15-43)$ & $69.3 \pm 10.2$ & $17(48.6)$ & \multirow{2}{*}{35} \\
\hline & 3-peaked P & $29.6(11-53)$ & $72.7 \pm 12.8$ & $18(51.5)$ & \\
\hline \multirow{3}{*}{$\begin{array}{l}\text { Atrial } \\
\text { Septal } \\
\text { Defect }\end{array}$} & 2-peaked P & $13.3(4.8-32)$ & $83.5 \pm 10.9$ & $33(64.7)$ & \multirow{3}{*}{51} \\
\hline & 3-peaked P & $19.5(9-29)$ & $80.0 \pm 10.0$ & $12(23.5)$ & \\
\hline & 4-peaked P & $20.7(14-26)$ & $67.7 \pm 10.7$ & $6(11.8)$ & \\
\hline \multirow{2}{*}{$\begin{array}{l}\text { Tetralogy } \\
\text { of Fallot }\end{array}$} & 2-peaked $P$ & $11.3(1.4-27)$ & $84.1 \pm 21.9$ & $16(72.7)$ & \multirow{2}{*}{22} \\
\hline & 3-peaked P & $13.3(8-20)$ & $70.2 \pm 8.8$ & $6(27.3)$ & \\
\hline \multirow{2}{*}{$\begin{array}{l}\text { Pulmonary } \\
\text { Stenosis }\end{array}$} & 2-peaked P & $13.4(7-23)$ & $69.5 \pm 10.8$ & $8(72.7)$ & \multirow{2}{*}{11} \\
\hline & 3-peaked P & $23.3(18-32)$ & $64.0 \pm 12.8$ & $8(27.3)$ & \\
\hline
\end{tabular}


at surgical operation in the First Department of Surgery of Kyushu University Hospital.

2. Recording of ECG, VCG and SVECG

ECG of the standard 12 leads and VCG with the Frank system ${ }^{5}$ were recorded for all subjects. The SVECG was recorded by a 4 channel heat writing recorder, simultaneously with the 3 scalar ECG's with a paper speed of $100 \mathrm{~mm}$ per second. The spatial velocity, $\mathrm{V}(\mathrm{mV} / \mathrm{sec})$, is given by the following formula ${ }^{6}$ :

$$
V=\sqrt{\left(\frac{d X}{d t}\right)^{2}+\left(\frac{d Y}{d t}\right)^{2}+\left(\frac{d Z}{d t}\right)^{2}}
$$

where $X, Y$ and $Z$ denote 3 scalar ECG's of the Frank system. The time constant of the differentiating circuit was $10 \mathrm{msec}$ for the atrial wave?, 6 The SVECG was calibrated with a $4 \mathrm{~Hz}$ sine wave generator and calculated by the following formu$1 a^{6}$ :

$$
V=\omega \cdot E=2 \pi \cdot f \cdot E
$$

where V: spatial velocity, $\omega$ : angular velocity, $\mathrm{f}$ : calibration frequency, and $E: 1 / 2$ of calibration voltage.

In the present study the $P$ wave of SVECG was classified into 3 types as seen in normal subjects: two-peaked, three-peaked, and fourpeaked patterns. Each peak of the atrial wave of the SVECG was designated as $\mathbf{P}_{1}, \mathrm{P}_{2}, \mathrm{P}_{3}$ and $\mathrm{P}_{4}$ respectively. Measurements were thus made for the following parameters: height of each peak, time intervals from the beginning of the $\mathrm{P}$ wave to each peak and each nadir, and the ratio of the height of the first peak to that of the terminal peak. The spatial velocity and time interval of the highest peak and duration of the $P$ wave of SVECG were also measured as Peak SV, Peak Time, and SV-Pd respectively (Fig. 1). These parameters in the atrial overload were compared statistically with those in normaal subjects.

\section{RESULTS}

\section{Atrial SVECG in Mitral Stenosis}

Thirty-five patients with MS aged 11 to 53 were studied and all were undergone cardiac catheterization (Table I). The pulmonary arterial systolic pressure was greater than $60 \mathrm{mmHg}$ in 5 , and greater than $70 \mathrm{mmHg}$ in 3 cases. The $\mathrm{P}$ wave findings in the standard ECG were shown in Table III.

The atrial SVECG in MS was divisible into 2 types: three-peaked pattern (group MS3) and four-peaked pattern (group MS4), which comprise 51.4 and 48.6 per cent of the total cases



Fig.2. SVECG in mitral stenosis.

MS4 and MS3 with or without marked PH: the P wave of SVECG of fourpeaked and three-peaked patterns in mitral stenosis with or without marked pulmonary hypertension. QRS complex was saturated due to large amplification. 
A

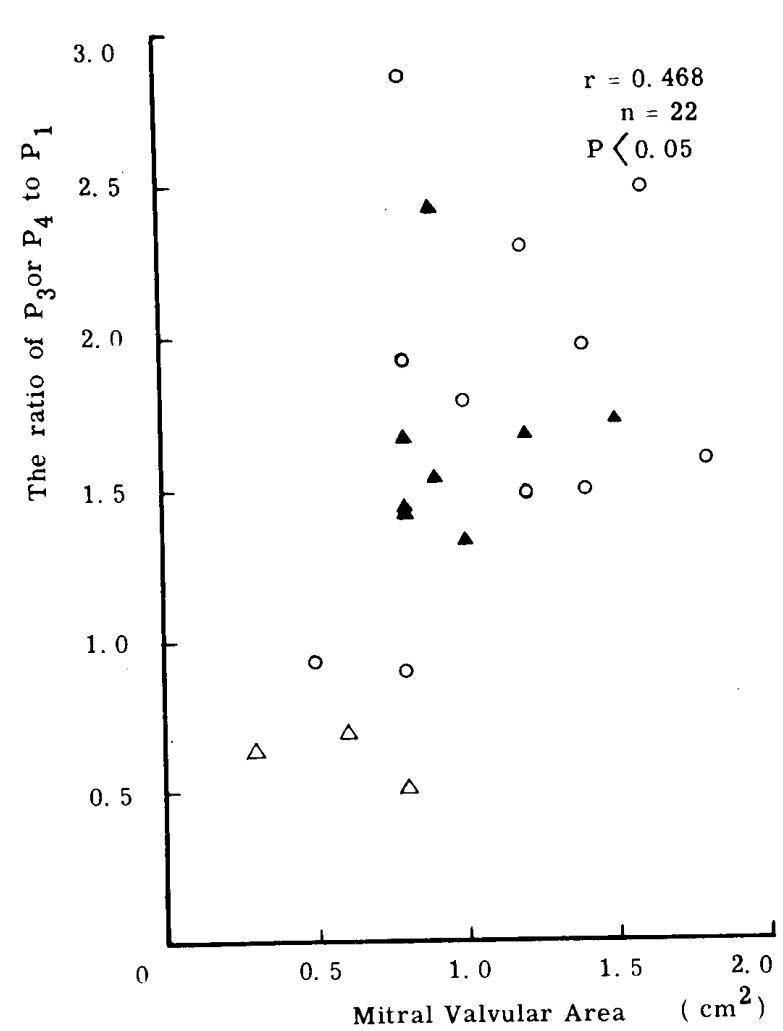

B

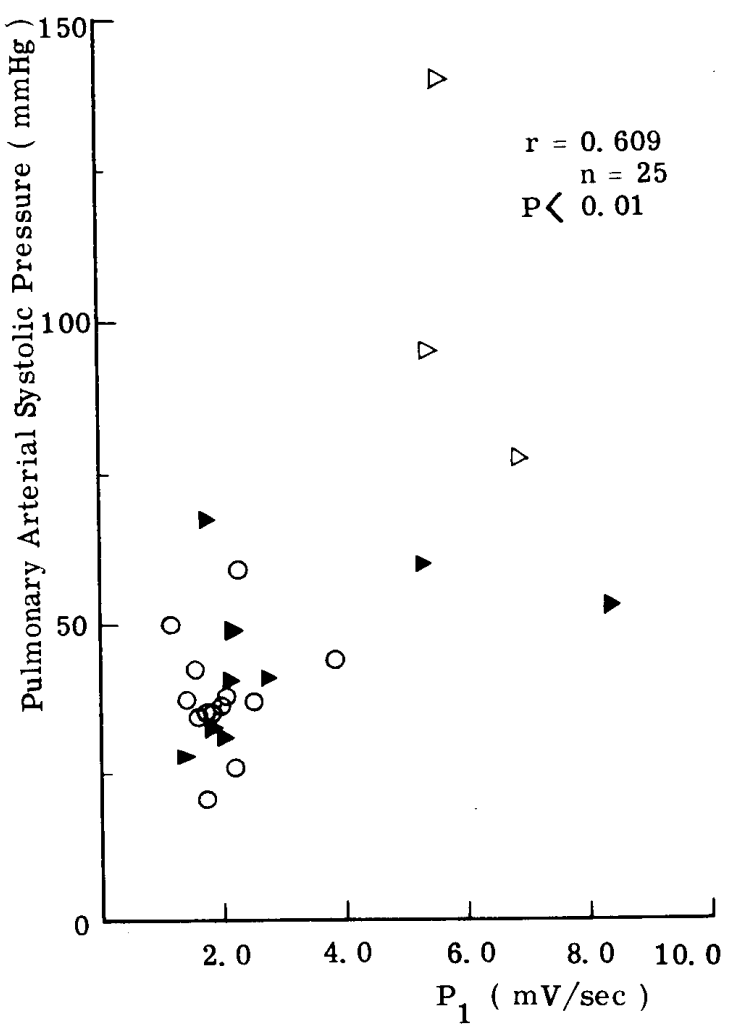

Fig.3. Correlations between the ratio of $P_{3}$ or $P_{4}$ to $P_{1}$ and mitral valvular area measured at surgery (A), and between the amplitude of $P_{1}$ and pulmonary arterial systolic pressure (B) in MS.

$O$ : group MS4, $\wedge$ : group MS3 without marked pulmonary hypertension.

$\triangle$ : group MS3 with marked pulmonary hypertension.

TABLE II HEMODYNAMIC DATA IN SUBGROUPS OF MS, ASD, TF AND PS

\begin{tabular}{lcccc}
\hline $\begin{array}{l}\text { Subgroups of } \\
\text { the atrial SVECG }\end{array}$ & RAMP & RVSP & PASD & LAMP \\
& Mean $\pm S D(n)$ & Mean $\pm S d(n)$ & Mean $\pm S D(n)$ & Mean $\pm S D(n)$ \\
\hline MS4 & $1.8 \pm 2.8(13)$ & $44.8 \pm 10.5(13)$ & $38.1 \pm 9.6(13)$ & $20.3 \pm 6.7(13)$ \\
$M S 3$ & $3.4 \pm 5.2(12)$ & $64.5 \pm 31.5(12)$ & $59.6 \pm 32.3(12)$ & $23.0 \pm 8.9(12)$ \\
\hline ASD2 & $3.9 \pm 2.1(32)$ & $39.8 \pm .9 .0(32)$ & $32.2 \pm 7.1(32)$ & $7.1 \pm 2.9(28)$ \\
ASD3 & $4.6 \pm 3.2(11)$ & $45.0 \pm 12.3(11)$ & $37.5 \pm 13.0(10)$ & $7.4 \pm 3.5(10)$ \\
ASD4 & $4.2 \pm 2.5(6)$ & $46.8 \pm 7.8(6)$ & $33.8 \pm 7.8(6)$ & $7.7 \pm 3.3(5)$ \\
\hline$T F 2$ & $4.2 \pm 3.7(16)$ & $124.2 \pm 24.2(16)$ & $13.9 \pm 9.4(5)$ & $7.2 \pm 4.7(10)$ \\
$T F 3$ & $3.5 \pm 2.8(6)$ & $97.3 \pm 26.7(6)$ & $14.0 \pm 7.4(4)$ & $5.9 \pm 4.0(5)$ \\
\hline$P S 2$ & $4.8 \pm 3.7(8)$ & $125.8 \pm 61.4(8)$ & $18.8 \pm 6.7(7)$ & $6.7 \pm 3.6(8)$ \\
& $1.0 \pm 1.0(3)$ & $91.3 \pm 29.2(3)$ & $13.2 \pm 3.6(3)$ & $2.2 \pm 1.0(3)$ \\
\hline
\end{tabular}

respectively (Fig. 2). It is noted the four-peaked pattern was more frequently observed in MS than in the normal subjects, and no two-peaked pattern was found even in the cases with marked pulmonary hypertension (Table IV).

In 28 cases $(80.0 \%)$ of MS group, $\mathrm{P}_{\mathbf{3}}$ and/or

Japanese Circulation Journal Vol. 37, July 1973 
TABLE III THE P WAVE IN THE STANDARD ECG IN SUBGROUPS OF NORMAL. SUBJECTS AND THE PATIENTS WITH ATRIAL OVERLOAD

\begin{tabular}{|c|c|c|c|c|c|c|c|}
\hline \multirow{3}{*}{$\begin{array}{l}\text { Subgroup } \\
\text { of } \\
\text { Subject }\end{array}$} & \multicolumn{3}{|c|}{ Height of the P wave } & \multirow{2}{*}{\multicolumn{2}{|c|}{$\begin{array}{c}\text { Peaked P wave } \\
\text { in the standard leads }\end{array}$}} & \multirow{3}{*}{$\begin{array}{c}\text { Duration } \\
\text { of the } P \\
\text { wave exceed } \\
0.12 \mathrm{sec}\end{array}$} & \multirow{3}{*}{$\begin{array}{l}\text { The P-R } \\
\text { interval } \\
\text { exceed } \\
0.20 \mathrm{sec}\end{array}$} \\
\hline & \multicolumn{2}{|c|}{ in lead II } & \multirow{2}{*}{$\begin{array}{l}\text { in lead } V I \\
\text { exceed } \\
0.20 \mathrm{mV}\end{array}$} & & & & \\
\hline & $\begin{array}{c}\text { exceed } \\
0.25 \mathrm{mV}\end{array}$ & $\begin{array}{l}\text { from } 0.24 \\
\text { to } 0.20 \mathrm{mV}\end{array}$ & & $\begin{array}{l}\text { exceed } \\
0.20 \mathrm{mV}\end{array}$ & $\begin{array}{l}\text { does not } \\
\text { exceed } \\
0.20 \mathrm{mV}\end{array}$ & & \\
\hline N4 & 0 & 0 & 0 & 0 & 0 & 0 & 0 \\
\hline N3 & 0 & 0 & 0 & 0 & 0 & 0 & 0 \\
\hline N2 & 0 & 2 & 0 & 1 & 1 & 0 & 0 \\
\hline$M S 4$ & 1 & 3 & 1 & 0 & 0 & 13 & 1 \\
\hline$M S 3$ & 6 & 4 & 1 & 7 & 0 & 10 & 2 \\
\hline$A S D 2$ & 1 & 6 & 13 & 12 & 10 & 6 & 5 \\
\hline$A S D 3$ & 0 & 2 & 1 & 1 & 2 & 2 & 4 \\
\hline$A S D 4$ & 0 & 0 & 1 & 1 & 1 & 4 & 3 \\
\hline$T F 2$ & 4 & 3 & 8 & 9 & 4 & 0 & 0 \\
\hline$T F 3$ & 3 & 0 & 2 & 3 & 3 & 0 & 0 \\
\hline PS2 & 1 & 2 & 2 & 3 & 3 & 1 & 0 \\
\hline PS3 & 0 & 1 & 1 & 0 & 0 & 1 & 0 \\
\hline
\end{tabular}

$\mathrm{P}_{4}$ were the highest. The spatial velocity of the left atrial component $\left(\mathrm{P}_{3}\right.$ and/or $\left.\mathrm{P}_{4}\right)$ was significantly correlated with size of mitral valvular area ascertained at surgery $(\mathrm{r}=0.468, \mathrm{n}=22, \mathrm{P}<0.05$, Fig. 3A). The spatial velocity of the right atrial component $\left(\mathrm{P}_{1}\right)$ was well correlated with pulmonary arterial systolic pressure $(\mathrm{r}=0.609, \mathrm{n}=$ 25 , P $<0.01$, Fig. 3 B), and also with right ventricular systolic pressure and right ventricular mean pressur $(\mathrm{r}=0.616, \mathrm{n}=25, \mathrm{P}<0.01: \mathrm{r}=0.641, \mathrm{n}=$ $25, \mathrm{P}<0.01$ respectively). With regards to intracardiac pressures and operation finding, however, no significant difference was found between group MS3 and group MS4, except for 3 cases of biatrial overloading due to marked pulmonary hypertension (Table II).

A. Four-Peaked Pattern (group MS4): In the standard ECG, 13 cases $(76.5 \%)$ met well the Morris' criteria for left atrial overload? In this subgroup the pulmonary arterial systolic pressure did not exceed $60 \mathrm{mmHg}$ in any case and mitral. valvular area was ascertained at surgical operation in 11 cases and was averaged as $1.14 \pm 0.40 \mathrm{~cm}^{2}$.

In group MS4, $\mathrm{P}_{\mathbf{4}}$ or $\mathrm{P}_{\mathbf{3}}$ was the highest among 4 peaks in 14 cases $\left(82.4 \%\right.$ ), and $P_{4}$ was higher than $\mathrm{P}_{1}$ significantly $(\mathrm{P}<0.01) \mathrm{P}_{4}$ and $\mathrm{P}_{2}$ were also higher than those in group $\mathrm{N} 4$ significantly $(\mathrm{P}<0.05$ and $\mathrm{P}<0.05)$. The ratio of $\mathrm{P}_{3} / \mathrm{P}_{1}$ and $\mathrm{P}_{4} / \mathrm{P}_{1}$ in group MS4 was larger than in group N4 $(\mathrm{P}<0.01$ and $\mathrm{P}<0.05) . \quad \mathrm{P}_{1}$ time in this subgroup did not exceed $35 \mathrm{msec}$ in 13 cases $(76.5 \%)$ and did not differ from than in group $\mathrm{N} 4$, but $\mathrm{Nd} 1$ time exceeded $35 \mathrm{msec}$ in 12 cases and increased in duration compared with in the control group $(\mathrm{P}<0.01) . \mathrm{P}_{2}$ time, $\mathrm{P}_{3}$ time, $\mathrm{P}_{4}$ time and SV-Pd increased significantly in duration in this subgroup compared with those in group N4 $(\mathbf{P}<0.01, \quad \mathrm{P}<0.001, \mathrm{P}<0.001$ and $\mathrm{P}<0.001$, respectively).

B. Three-Peaked Pattern (group MS3): In the standard ECG only 4 cases $(22.2 \%)$ met well the Morris' criteria for left atrial overload? In this subgroup the pulmonary systolic pressure exceeded $70 \mathrm{mmHg}$ in 3 cases and mitral valvular area was measured at surgical operation in 11 cases and was averaged as $0.87 \pm 0.31 \mathrm{~cm}^{2}$.

In group MS3, $\mathrm{P}_{\mathbf{3}}$ was the highest among 3 peaks in 15 of 18 cases $(83.3 \%)$ and was higher than $P_{1}$ significantly $(P<0.01) . P_{1}$ was the highest in 3 cases complicated with marked 
TABLE IV SPATIAL VELOCITY AND TIME INTERVAL OF THE P W AVE OF SVECG IN SUB-

\begin{tabular}{|c|c|c|c|c|c|c|c|}
\hline & & \multicolumn{3}{|c|}{ Normal } & \multicolumn{3}{|c|}{ Mitral Stenosis } \\
\hline & & $\begin{array}{c}N 4 \\
(20 \text { cases })\end{array}$ & $\begin{array}{c}\text { N3 } \\
(35 \text { cases })\end{array}$ & $\begin{array}{c}N 2 \\
\text { (6 cases) }\end{array}$ & $\begin{array}{c}\text { MS4 } \\
\text { (17 cases) }\end{array}$ & $\begin{array}{l}\text { MS3 without } \\
\text { marked PH } \\
\text { (15 cases) }\end{array}$ & $\begin{array}{l}\text { MS3 with } \\
\text { marked PH } \\
\text { (3 cases) }\end{array}$ \\
\hline \multirow{5}{*}{$\begin{array}{l}\text { Spatial } \\
\text { Velocity }\end{array}$} & $P_{1}$ & $2.04 \pm 0.66$ & $1.79 \pm 0.77$ & $3.88 \pm 1.54$ & $1.95 \pm 0.62$ & $2.69 \pm 1.93$ & $5.91 \pm 0.82$ \\
\hline & $P_{2}$ & $1.67 \pm 0.67$ & $1.85 \pm 0.86$ & $3.55 \pm 0.96$ & $2.30 \pm 0.98$ & $2.97 \pm 2.04$ & $4.57 \pm 2.30$ \\
\hline & $P_{3}$ & $1.76 \pm 0.88$ & $2.34 \pm 1.04$ & & $2.34 \pm 0.81$ & $5.50 \pm 2.52$ & $3.65 \pm 0.99$ \\
\hline & $P_{4}$ & $2.17 \pm 0.80$ & & & $3.45 \pm 1.71$ & & \\
\hline & Peak & $2.48 \pm 0.83$ & $2.58 \pm 0.90$ & $4.22 \pm 1.36$ & $3.76 \pm 1.48$ & $5.05 \pm 2.52$ & $5.91 \pm 0.82$ \\
\hline \multirow{3}{*}{ Ratio } & $P_{2} / P_{1}$ & & & $0.99 \pm 0.30$ & & & \\
\hline & $P_{3} / P_{1}$ & $0.89 \pm 0.36$ & $1.70 \pm 1.50$ & & $1.23 \pm 0.37$ & $2.23 \pm 0.99$ & $0.61 \pm 0.09$ \\
\hline & $P_{4} / P_{1}$ & $1.16 \pm .0 .47$ & & & $1.88 \pm 1.01$ & & \\
\hline \multirow{9}{*}{$\begin{array}{l}\text { Time } \\
\text { Interval }\end{array}$} & $P_{1}$ & $25.3 \pm 5.3$ & $22.6 \pm 6.8$ & $36.8 \pm 11.2$ & $28.2 \pm 7.5$ & $30.8 \pm 10.8$ & $37.0 \pm 7.8$ \\
\hline & $P_{2}$ & $47.5 \pm 6.3$ & $47.5 \pm 8.3$ & $81.3 \pm 13.3$ & $57.6 \pm 9.7$ & $69.1 \pm 13.1$ & $74.3 \pm 4.9$ \\
\hline & $P_{3}$ & $70.1 \pm 8.1$ & $87.2 \pm 12.2$ & & $86.7 \pm 8.7$ & $109.9 \pm 10.6$ & $102.7 \pm 11.0$ \\
\hline & $P_{4}$ & $96.1 \pm 7.8$ & & & $116.9 \pm 8.8$ & & \\
\hline & Peak & $64.1 \pm 31.4$ & $65.0 \pm 29.2$ & $59.5 \pm 32.0$ & $96.9 \pm 30.2$ & $109.9 \pm 10.6$ & $37.0 \pm 7.8$ \\
\hline & $N d 1$ & $36.6 \pm 6.0$ & $34.3 \pm 7.8$ & $58.8 \pm 10.7$ & $41.8 \pm 9.3$ & $45.2 \pm 13.6$ & $60.0 \pm 13.7$ \\
\hline & $N d 2$ & $59.6 \pm 7.4$ & $65.2 \pm 8.7$ & & $73.2 \pm 9.3$ & $86.1 \pm 12.0$ & $92.7 \pm 9.1$ \\
\hline & $N d 3$ & $80.9 \pm 9.4$ & & & $101.3 \pm 9.7$ & & \\
\hline & $S V \cdot P d$ & $136.8 \pm 12.1$ & $131.9 \pm 19.9$ & $142.0 \pm 23.3$ & $156.3 \pm 9.6$ & $150.1 \pm 14.0$ & $142.7 \pm 9.3$ \\
\hline
\end{tabular}

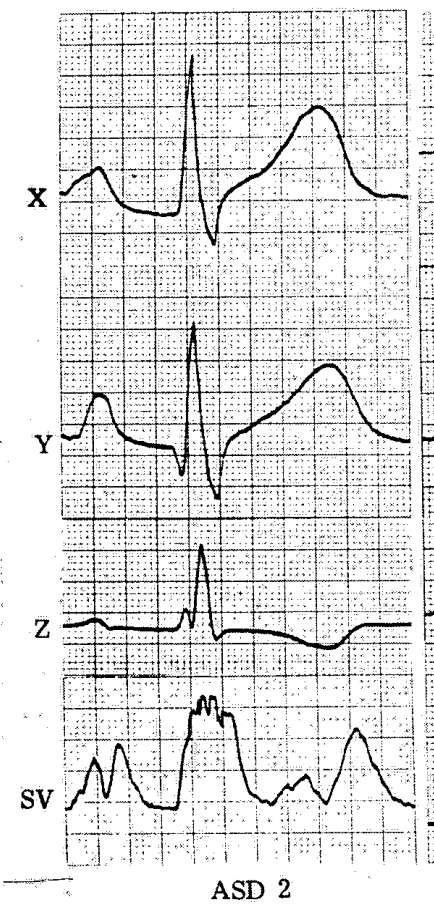

ASD 2

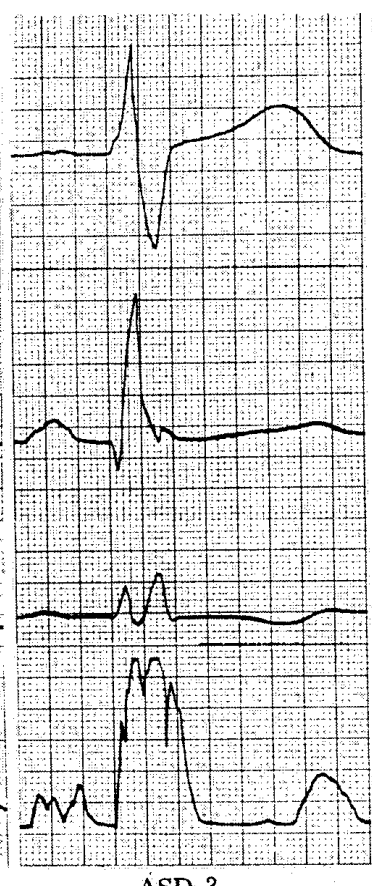

ASD 3



ASD 4

Fig.4. SVECG in atrial septal defect.

ASD2, ASD3 and ASD4: The P wave of SVECG of two-peaked, three-peaked and four-peaked patterns in ASD respectively. 
GROUPO OF NORMAL SUJECTS AND THE PATIENTS WITH ATRIAL OVERLOAD (Mean \pm S.D.).



pulmonary hypertension, whose hemodynamic data were: pulmonary arterial systolic pressure; average $104.2 \mathrm{mmHg}(77.5$ to $140.0 \mathrm{mmHg}$ ) and left atrial mean pressure; average $35.4 \mathrm{mmHg}$ (28.8 to $40.0 \mathrm{mmHg}$ ).

In group MS3 without marked pulmonary hypertension, $\mathrm{P}_{\mathbf{3}}$ was higher than in group N3 $(P<0.01)$, but $P_{1}$ and $P_{2}$ did not differ significantly from those in group N3. $P_{1}$ time did not exceed $35 \mathrm{msec}$ in duration in 11 and $\mathrm{Ndl}$ time did $35 \mathrm{msec}$ in 12 of 15 cases without marked pulmonary hypertension. $\mathrm{P}_{2}$ time, $\mathrm{P}_{3}$ time and SV-Pd increased in duration compared with those in group $\mathrm{N} 3(\mathrm{P}<0.01, \mathrm{P}<0.001$ and $\mathrm{P}<0.01$ respectively).

2. Atrial SVECG in Atrial Septal Defect

Twenty-four male and 27 female patients with ASD were studied (Table I). In 49 of 51 cases, diagnosis was made by cardiac catheterization, and in 46 cases was ascertained at surgical operation. In 3 cases partial anomalous drainage of pulmonary vein was present. The right ventricular systolic pressure was $41.8 \pm 9.9 \mathrm{mmHg}$, exceeding $60 \mathrm{mmHg}$ in only one case and was shown in subgroups in Table II. The systolic pressure gradient across the pulmonary valve



Fig.5. Correlation between the peak spatial velocity of the two-peaked pattern and the right ventricular systolic pressure in ASD.

Japanese Circulation Journal Vol. 37, July 1973 


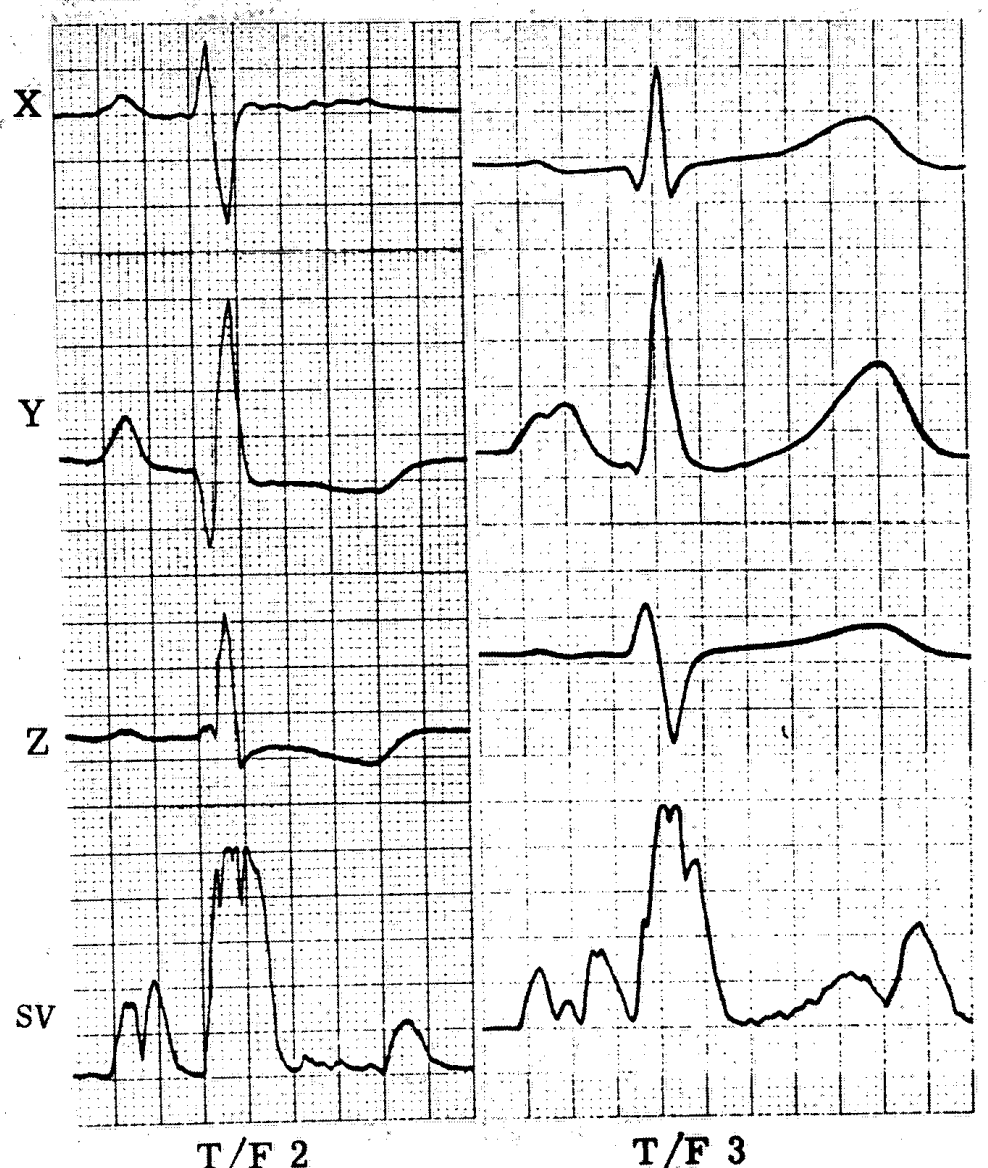

Fig.6. SVECG in tetralogy of Fallot.

TF2 and TF3: The P wave of SVECG of two-peaked and three-peaked patterns in TF.

exceeded $20 \mathrm{mmHg}$ in only one case. The "a" wave pressure in the right atrium was greater than $10.0 \mathrm{mmHg}$ in 7 cases; in 4 of them $P$ waves were less than $0.20 \mathrm{mV}$ in the standard ECG. The amplitude of the $\mathbf{P}$ wave was above $0.25 \mathrm{mV}$ in only one cases $(2.0 \%)$ and above $0.20 \mathrm{mV}$ in 9 cases $(17.6 \%)$ in lead II (Table III).

The atrial SVECG in ASD was composed of 3 types: two-peaked (group ASD2), three-peaked (group ASD3) and four-peaked patterns (group ASD4) (Fig. 4, Table IV).

A. Two-Peaked Pattern (group ASD2): The two-peaked pattern was recorded in 33 cases $(64.7 \%)$ and its incidence was significantly higher than in normal subjects $(\mathrm{P}<0.001)$ (Table I). $\mathrm{P}_{1}$ was higher than $P_{2}$ in 12 cases $(36.4 \%)$ and vice versa in 21 cases $(63.6 \%)$ of this subgroup, but no significant difference was revealed in spatial velocity between both peaks. Peak SV in group ASD2 was higher than in group ASD4 $(\mathrm{P}<0.02)$ (Table IV). The right ventricular systolic pressure exceeded $50 \mathrm{mmHg}$ in 6 of 32 cases and atrial septal defect area was measured at surgical operation in 31 cases and was $5.2 \pm 2.7 \mathrm{~cm}^{2}$. Peak SV was correlated with the right ventricular systolic pressure $(\mathrm{r}=0.394, \mathrm{n}=32, \mathrm{P}<0.05)$ (Fig. 5). $\mathrm{P}_{1}$ time, $\mathrm{P}_{2}$ time, $\mathrm{Nd} 1$ time and SV-Pd in group ASD2 almostly coincided with those of group N2 respectively (Table IV).

B. Three-Peaked Pattern (group ASD3): The right ventricular systolic pressure exceeded $50 \mathrm{mmHg}$ in 2 cases, and atrial septal defect area was measured in 11 cases and was $4.3 \pm 1.4 \mathrm{~cm}^{2}$. $P_{3}$ was the highest in 8 cases $(66.7 \%)$ of this subgroup like in group $\mathrm{N} 3$, but $\mathrm{P}_{1}$ and $\mathrm{P}_{2}$ were much higher than in group $\mathrm{N} 3(\mathrm{P}<0.001$ and $\mathrm{P}<0.01$ ). $\mathrm{P}_{1}$ time did not exceed $35 \mathrm{msec}$ in 11 but $\mathrm{Nd} 1$ time exceeded $35 \mathrm{msec}$ in 8 of 12 cases. C. Four-Peaked Pattern (group ASD4): No case of this subgroup showed tall and peaked $P$ wave in the standard ECG (Table III). The right ventricular systolic pressure exceeded $50 \mathrm{mmHg}$ in 3 cases and atrial septal defect area was measured in 4 cases and was $7.3 \pm 4.2 \mathrm{~cm}^{2} \mathrm{P}_{1}$ is 


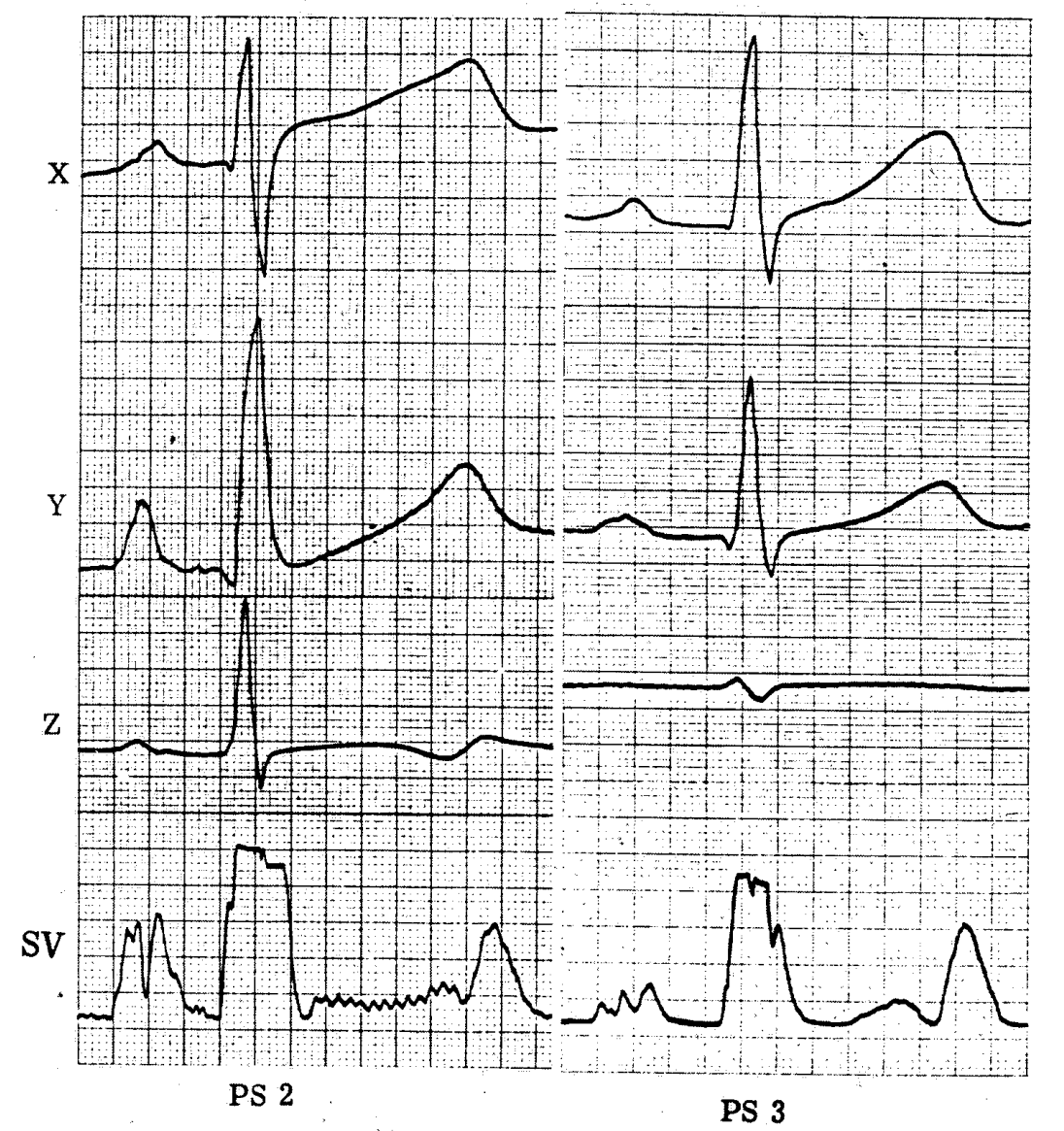

Fig.7. SVECG in pulmonary stenosis. PS2 and PS3: the P wave of SVECG of two-peaked and three-peaked patterns in PS.

not significantly higher in group ASD4 than in group N4 but is the highest in 4 of group ASD4 $(66.7 \%)$.

3. Atrial SVECG in Tetralogy of Fallot

Thirteen males and 9 females with tetralogy of Fallot aged 1.4 to 27, including one case of acyanotic type, were subjected to the study (Table I). Four cases had sinus tachycardia of more than 100 beats per minute and high hemoglobin content of peripheral blood of more than $20.0 \mathrm{~g} / \mathrm{dl}$. In 7 cases $(31.8 \%)$ the $P$ wave was more than $0.25 \mathrm{mV}$ in lead II (Table III).

The atrial SVECG of TF group was classified into 2 types: two-peaked (group TF2) and three-peaked patterns (group TF3) which comprise 72.7 and 27.3 per cent of the total respectively (Fig. 6, Table IV).

A. Two-Peaked Pattern (group TF2): No significant difference in the incidence of tall and peaked $P$ wave in the standard ECG between group TF2 and group TF3 (Table III). The right ventricular systolic pressure in group TF2 varied from 92.5 to $170.0 \mathrm{mmHg}$, and was significantly higher than in group TF3 $(\mathrm{P}<0.05)$ (Table II). Five cases $(31.3 \%)$ had high "a" wave pressure in the right atrium of more than $10.0 \mathrm{mmHg}$, and $12(75.0 \%)$ had right ventricular pressure exceeding the systemic pressure.

In group $\mathrm{TF} 2, \mathrm{P}_{1}$ time did not exceed 35 msec in 7 cases $(43.8 \%)$ but Ndl time did not exceed $60 \mathrm{msec}$ in $14(87.5 \%)$ and $\mathrm{P}_{2}$ time did $75 \mathrm{msec}$ in only $4(25.0 \%)$. There was no significant difference in $\mathrm{P}_{1}, \mathrm{P}_{2}$, Peak $\mathrm{SV}$ and $\mathrm{P}_{1}$ time between group TF2 and group N2. In group TF2, however, Nd1 time, $\mathrm{P}_{2}$ time and SV-Pd decreased in duration slightly as compared with in group $\mathrm{N} 2 \quad(\mathrm{P}<0.10, \mathrm{P}<0.10$ and $\mathrm{P}<0.05$ respectively) (Fig.8).

B. Three-Peaked Pattern (group TF3): The right ventricular systolic pressure in this subgroup ranged from 70 to $135 \mathrm{mmHg}$ and was lower than in group TF2 was mentioned above (Table II). $\mathrm{P}_{1}$ was the highest in 2 and was higher in group $\mathrm{TF} 3$ than in group $\mathrm{N} 3(\mathrm{P}<0.05)$. In group TF3, $\mathrm{P}_{3}$ was the highest in 3 , but $\mathrm{P}_{2}$ and $\mathbf{P}_{3}$ did not significantly increase in amplitude as 



Fig.8. Scattergram of the spatial velocity and time interval of two-peaked patterns of the atrial SVECG in normal and in atrial overload.

compared with in group N3 and in group ASD3. $\mathrm{Nd} 2$ and $\mathrm{P}_{3}$ time were shorter in this subgroup than in group N3 and in group ASD3 $(\mathrm{P}<0.05$ and $\mathbf{P}<0.05$ ) (Table IV).

4. Atrial SVECG in pure Pulmonary Stenosis

The $P$ wave of this group exceeded $0.25 \mathrm{mV}$ in only one and was peaked in $6(54.5 \%)$ in lead II (Table III). Eleven cases of pure pulmonary stenosis were diagnosed by cardiac catheterization and selective angiocardiography, in 10 among which the diagnosis was ascertained at surgical operation. The right ventricular systolic pressure was shown in subgroups in Table II and was less than $80 \mathrm{mmHg}$ in 3,80 to $119 \mathrm{mmHg}$ in 4 , and more than $120 \mathrm{mmHg}$ in 4 , in which 3 with right ventricular hypertension far beyond the systemic pressure were included.

The atrial SVECG in PS group was classified into 2 types as in ASD and TF groups: twopeaked (group PS2) and three-peaked patterns (PS3), which comprise 8 cases $(72.7 \%)$ and 3 (27.3\%) respectively (Fig. 7, Table I).

A. Two-Peaked Pattern (group PS2): The right ventricular systolic pressure varied from 66 to $216 \mathrm{mmHg}$, exceeding the systemic pressure in 3 cases. The size of pulmonary valvular area was 
measured in all cases at surgery and ranged from 0.2 to $0.8 \mathrm{~cm}^{2}$, with an average of $0.35 \pm 0.20 \mathrm{~cm}^{2}$. being smaller in group PS2 than in group PS3 $(\mathrm{P}<0.05)$. The incidence of the two-peaked pattern in PS group is as high as in TF group compared with in normal subjects. SV-Pd decreased slightly in group PS2 than in group $\mathrm{N} 2 \quad(\mathrm{P}<0.10)$. However, there was no significant difference in spatial velocity of each peak and time interval except for SV-Pd between group PS2 and group N2 (Fig.8).

B. Three-Peaked Pattern (group PS3): A female aged 32 showed a right ventricular systolic pressure of $125 \mathrm{mmHg}$ less than the systemic pressure, and the remaining 2 with pulmonary valvular area of $0.8 \mathrm{~cm}^{2}$ showed right ventricular systolic pressure less than $80 \mathrm{mmHg}$.

There was no significant difference in spatial velocity and time interval among group ASD3, group TF3 and group PS3 (Table IV).

\section{Discussion}

1. Artial SVECG of the Left Atrial Overloading

As for the vectorcardiographic concepts of left atrial overloading, it has been accepted that the terminal $\mathbf{P}$ vector increases in magnitude and is displaced significantly to the leftward and posteriorly?-15 In the atrial SVECG of MS, three-peaked and four-peaked patterns were recorded in approximately equal numbers of cases, the latter pattern being noted more frequently than in the control subjects.

Marked increase in duration of $P_{2}$ time, $P_{3}$ time and $\mathrm{P}_{4}$ time in the atrial SVECG of left atrial overloading may relect the prolongation of time for excitation of overloaded left atrium and disturbance in the inter- and intra-auricular conduction. Significant increase in spatial velocity of $\mathrm{P}_{3}$ and $\mathrm{P}_{4}$, is attributed to the leftward and posterior displacement and increase in magnitude of the left atrial vectors. The first peak, which represents mainly the depolarization of the right atrium, does not differ significantly from that in normal subjects, resulting in increased ratio of $\mathrm{P}_{3} / \mathrm{P}_{1}$ and/or $\mathrm{P}_{4} / \mathrm{P}_{1}$ in MS without pulmonary hypertension.

Advanced MS is usually accompanied by pulmonary hypertension, leading to the right atrial overloading. When the cases of MS with pulmonary hypertension are included, the height of $P_{1}$ increases with elevation of pulmonary arterial systolic pressure, right ventricular systolic pressure and right ventricular mean pressure (Fig. 3).
Therefore, it can be mentioned in the atrial SVECG that the spatial velocity of the left atrial component $\left(\mathrm{P}_{3}\right.$ and/or $\left.\mathrm{P}_{4}\right)$ increases first, and that of the right atrial component does not increase significantly in MS as compared with in normal subjects. In advanced cases of MS, however, the first peak was tallest, resulting in marked decrease in ratio of $\mathbf{P}_{3} / \mathbf{P}_{1}$, and its atrial SVECG was deformed to a much different pattern from that in typical MS (Fig.2).

2. Atrial SVECG of the Right Atrial Overloading

As characteristics of the right atrial overloading, significant increase in magnitude of the maximum $\mathbf{P}$ vector and anterior displacement and vertical position of the $\mathbf{P}$ loop were noted $8,9,11,12,14-17$ Sánches-Cascos and Deuchar ${ }^{18}$ and Anselmi et al ${ }^{19}$ classified the atrial overloading into systolic and diastolic types applying the concept of ventricular systolic and diastolic overloadings proposed by Cabrera and Monroy. ${ }^{20}$ Here the atrial SVECG is discussed in ASD, TF and PS separately.

A. Atrial SVECG in ASD: No significant difference was disclosed in pressure in pulmanary artery, right ventriculum, and right atrium between group ASD2, group ASD3 and group ASD4. However it is interesting to note that the incidence of two-peaked pattern in ASD group $(65 \%)$ is as high as in the TF $(73 \%)$ and PS (73\%) groups.

Four-peaked and three-peaked patterns are observed in relatively few cases of ASD group. In group ASD4, $\mathrm{P}_{1}$ was the highest among 4 peaks in 4 of 6 cases, and $\mathrm{P}_{3}, \mathrm{P}_{4}$, and the ratio of $\mathrm{P}_{3} / \mathrm{P}_{1}$ and $\mathrm{P}_{4} / \mathrm{P}_{1}$ were not significantly increased unlike in group MS4. Though no significant difference was revealed in spatial velocity between group ASD3 and group MS3, in the former $\mathrm{P}_{2}$ time and $\mathrm{P}_{3}$ time were significantly shorter than in the latter $(P<0.01$, and $P<0.001)$. These findings discrimate ASD group from MS group, and suggest the existence of the left atrial overload to some extent, additional to the right atrial overload in ASD group.

No significant difference was also disclosed in spatial velocity between group TF2 and group ASD2, but in the former $\mathrm{P}_{2}$ time and SV-Pd decreased in duration significantly than in the latter $(\mathrm{P}<0.01$ and $\mathrm{P}<0.01)$. These findings suggest that the activation time of left atrium in ASD group does not prolong like in MS group but prolonges significantly as compared with in TF group. 
B. Atrial SVECG in Tetralogy of Fallot: In TF group marked elevation of right ventricular pressure is present and is leading secondary to systolic overloading of the right atrium, ${ }^{15,21}$ and also peaked and tall $P$ waves are recorded in many cases in the standard ECG 11,17,21-23 In the present study, about 73 per cent of the cases showed two-peaked pattern in the atrial SVECG.

The hemodynamic mechanism of right atrial overloading in TF is considered to differ from that in PS group, because of the arterial desaturation, 15,17 rheological changes of the blood due to the polycytemic syndrome, ${ }^{24,25}$ and different manner of ventricular contraction due to the right to left shunt at the ventricular level2 1 peculiarly seen in TF group. Therefore, the two-peaked morphology of the atrial SVECG in TF group cannot be attributed immediately to the right atrial overloading. In the present study, however, right ventricular systolic pressure in group TF2 was significantly higher than in group TF3 $(\mathrm{P}<0.05)$ (Table II). In TF group the incidence of two-peaked pattern was also as higher significantly as in ASD and PS groups than in the control group. There was no significant difference in spatial velocity of both peaks between group TF2 and PS2. This may due to that the hemodynamic severity of PS group was milder than of TF group in the present study.

C. Atrial SVECG in PS: It is generally known that in PS the right atrial overloading secondary to right ventricular overloading results in tall and peaked $P$ wave ${ }^{15,26}$ In the present study, however, the $P$ wave exceeded $0.25 \mathrm{mV}$ in few cases and was peaked in about half of the cases in the standard ECG. On the other hand, about 73 per cent of PS group showed the two-peaked pattern and no four-peaked pattern in the atrial SVECG. In group PS3, no case had right ventricular systolic pressure exceeding the systemic pressure and peaked $P$ wave in the standard ECG. It can be reasonably considered that the SVECG represents the severity of right atrial overload as a two-peaked pattern in PS group as seen in TF group.

\section{Acknowledgement}

The author wishes to express their sincere gratitudes to Professor Hiroyoshi Mori of Tokushima University and to Professor Toshiyuki Yanase and Dr. Motoharu Tetsuoh of Kyushu University for their kind guidance and also to the members of the cardiovascular research of the First Department of Internal Medicine, Department of Cardiology, Department of Pediatrics, and the First Department of Surgery of Kyushu University
Hospital, for their kind cooperation.

\section{REFERENCES}

1. HELLERSTEIN, H. K. \& HAMLIN, R.: QRS component of the spatial vectorcardiogram and of the spatial magnitude and velocity electrocardiograms of the normal dog, Am. J. Cardiol. 6: 1049, 1960.

2. SANO, T., SUZUKI, F., HIROKI, T., \& MINAMI, S.: Studies on the spatial velocity electrocardiograph (First report). Its clinical significance and newly constructed recording apparatus. (Abstr) Jap. Circulation J. 28: 649, 1964. (in Japanese) (The 31 st Kanto-Koetsu Regional Meeting) of Jap. Circulation in Society, Nov. 30, 1963)

3. MORI, H., NAGAYAMA, T., \& NAKASONE, K:: Newly designed spatial velocity and acceleration electrocardiograph, (abstr) Jap. Circulation J. 31: 976, 1967. (in Japanese)(The 21 st Kyushu Regional Meeting of Jap. Circulation Society, Nov. 20, 1966)

4. YASUDA, H.: Spatial velocity electrocardiogram of the $P$ wave in normal subjects. (in Press)

5. FRANK, E.: An accurate, clinically practical system for spatial vectorcardiography, Circulation 13: 737, 1956.

6. MORI, H., NAGAYAMA, T., ODA, T., OHSHITA, K., SHIBATA, T., \& other six colleagues.: A nalog computer analysis of spatial vectorcardiogram: Spatial magnitude, velocity and acceleration electrocardiograph and its clinical applications. Jap. Circulation J. 32: 149, 1968.

7. MORRIS, J. J., Jr., ESTES, E. H., Jr., WHALEN, R. E., THOMPSON, H. K., Jr., \& McINTOSH, H. D.: P-wave analysis in valvular heart disease, Circulation 29: 242, 1964.

8. TAKAYASU, M.: Studies on the electorcardiogram recorded with the cathode ray oscillograph. Second report: On the left auricular predominance; Third report: On the right auricular predominance, Jap. Circulation J. 3: 381, 447, 1937. (in Japanese)

9. CHOU, T. C.\& HELM, R. A.: Clinical vectorcardiography, Grune and Stratton, New York. 1967.

10. GOOCH, A. S., CALATAYUD, J. B., CORMAN, P. A., SAUNDERS, J. L., \& CACERES, C. A.: Leftward shift of the terminal $P$ forces in the ECG associated with left atrial enlargement. Am. Heart J. 71: 727, 1966.

11. MASSIE, E. \& WALSH, T.J.: Clinical vectorcardiography and electrocard iography. Year Book Publishers. Chicago, 1960.

12. SANO, T., HELlERSTEIN, H. K., \& VAYDA, E.: $P$ vector loop in health and disease as studied by the technique of electrical dissection of the vectorcardiogram. (differential vectorcardiography). $\mathrm{Am}$. Heart J. 53: 854, 1975.

13. SUTNICK, A. I. \& SOLOFF, L. A.: Posterior rotation of the atrial vecor. An electrocardiographic sign of left ventricular filure. Circulation 26: 913 , 1962.

14. TOYAMA, S.: Vectorcardiogram and electrocardiogram. The Saishin-Igaku 19: 1506, 1964 (in Japanese).

15. ZIMMERMAN, H. A.: The auricular electrocardiogram, Thomas, Spring-Field. 1968. 
16. MORI, H. \& KAWAMADA, K.: Introduction of the P waves. Igaku-Shuppan-Sha, Tokyo. 1969 (in Japanese)

17. DeOLIVEIRA, J. M. \& ZIMMERMAN, H. A.: Auricular overload ins. Electrocardiographic analysis of 193 cases. Am. J. Cardiol. 3: 453, 1959.

18. SÁNCHEZ-CASCOS, A. \& DEUCHAR, D.: The P wave in atrial septal defect. Brit. Heart J. 25:202, 1963.

19. ANSELMI, G., MUÑOZ-ARMAS, S., SALAZAR, A., AMSELMI, A., DePISANI, F, \& BLANCO, P.: Electrocardiographic patterns of right atrial overloading in some congenital heart conditions. Am.J. Cardiol. 21: 628, 1968.

20. CABRERA, E. C. \& MONROY, J. R.: Systolic and diastolic loading of the heart. Am. Heart J. 43: $661,669,1952$.

21. MUÑNOZ-ARMAS, S., Del TORO, A., SODI-PALLARES, D., \& De La CRUZ, M. V.: Tetralogy of
Fallot and pulmonary stenosis with intact interventricular septum. Am. J. Cardiol. 21: 773, 1968.

22. TAUSSIG, H. B.: Congenital malformations of the heart. Volume II Specific malformations. Harvard Univ. Press. Cambridge, 1960.

23. WODDS, A.: The electrocardiogram in the tetralogy of Fallot. Brit. Heart J. 14: 193, 1952.

24. ISOGAI, Y., ICHIBA, K., IIDA, A., \& CHIKATSU, I.: Hemorrheology. Special reference to internal medicine. The Saishin-Igaku 24: 2097, 1969 (in Japanese).

25. NAKAMURA, Y.: Symposium on introduction of rheology into internal medicine. Rheology of the pulmonary circulation. J. Jap. Soc. Int. Med. 58: 1338, 1969 (in Japanese).

26. CAMPBELL, M.: Simple pulmonary stenosis. Pulmonary valvular stenosis with a closed ventricular septum. Brit. Heart J. 16: 273, 1954. 